\title{
Tendências de inovação em bibliotecas escolares: vertentes emergentes para ressignificar esses espaços
}

\author{
Innovation trends in school libraries: emerging trends to reframe these spaces \\ Gabriela Barbosa Carneiro \\ Graduada em Pedagogia pela Universidade de Brasília - UnB, Brasil. \\ E-mail: gabriela153838@gmail.com
}

\begin{abstract}
Tel Amiel
Doutorado em Instructional Technology pela University of Georgia, UGA, Estados Unidos. Professor da Faculdade de Educação da Universidade de Brasília - UnB, Brasil.

E-mail: $\underline{\text { amiel@unb.br }}$
\end{abstract}

\begin{abstract}
Resumo
Investigar possibilidades de inovação em espaços escolares é um movimento necessário para acompanhar as necessidades da sociedade contemporânea, que, mesmo com desigualdades, encontra-se cada vez mais imersa num universo de novas mídias. Este trabalho tem como objetivo geral investigar tendências de inovação em bibliotecas escolares, com foco em espaços de criação colaborativos. Especificamente, busca mapear quais as práticas de inovação têm sido implementadas nas bibliotecas escolares brasileiras e de que forma os conceitos de makerspace, hackerspace e Centro de Recursos têm sido incorporados pelas instituições escolares. Por meio de uma revisão sistemática de literatura, contemplando artigos, publicações em conferências ou resumos expandidos revisados por pares, além de teses e dissertações, publicados entre os anos 2000 e 2020 , em português, obteve-se 8 trabalhos que se enquadraram nos critérios de inclusão. As publicações indicaram que o makerspace e Centro de Recursos de Aprendizagem (quando se propõe a compor o planejamento e os objetivos do sistema educativo) são uma tendência promissora de inovação em bibliotecas escolares. Os trabalhos apontam que, para uma incorporação efetiva dessas vertentes, se faz necessário uma flexibilização do currículo, um processo de conscientização da comunidade escolar e a qualificação dos profissionais bibliotecários. Conclui-se que essa as vertentes aqui apresentadas ainda pouco presentes na literatura sobre bibliotecas escolas no Brasil mas, que já se mostram visíveis com exemplos efetivos em algumas instituições.
\end{abstract}

Palavras-chave: Biblioteca escolar. Inovação. Makerspace. Hackerspace. Centro de Recursos.

\begin{abstract}
Investigating possibilities for innovation in school spaces is a necessary movement to follow the needs of contemporary society, which, even with inequities, is increasingly immersed in new media. This paper has as its general objective the investigation of innovation trends in school libraries, focusing on collaborative creation spaces. Specifically, it seeks to map which innovation trends have been implemented in Brazilian school libraries and how the concepts of makerspace, hackerspace and Resource Center have been incorporated by school institutions. Through a systematic literature review, which included articles, publications in conferences or peerreviewed abstracts, as well as theses and dissertations, published between 2000 and 2020, in Portuguese, we obtained 8 papers that met the inclusion criteria. The publications indicated makerspace and Learning Resource Centers (when they take into consideration the planning and goals of educational systems) are a promising trend of innovation in school libraries. The studies point out that, for an effective incorporation of these trends, it is necessary to make the curriculum more flexible, to raise the awareness of the school community, and to qualify library professionals. We conclude that the aspects presented here are still little present in the literature on school libraries in Brazil, but are already visible with effective examples in some institutions.
\end{abstract}

Keywords: School library. Innovation. Makerspace. Hackerspace. Resource Center. 


\section{Introdução}

O conceito de biblioteca como um ambiente silencioso e que existe apenas para reunir livros e referências têm sido revisitado com o passar dos anos. Essa mudança de perspectiva se dá por meio de uma série de mudanças culturais, questões estruturais, físicas e relacionadas à recursos pedagógicos e tecnológicos que têm levado a novas caracterizações das bibliotecas no século XXI. De forma mais central, desde a Antiguidade, o conceito de biblioteca foi constituído como um ambiente de guarda de registros e livros de acesso exclusivo às classes de poder (OLIVEIRA, 2019). Entretanto, ao longo do tempo, essa concepção foi enfraquecida e a biblioteca torna-se um espaço agente de influência e transformação social.

Essa definição de biblioteca moderna, foi instituída através de quatro características: laicização, democratização, especialização e socialização, que juntas, cooperaram para dar início, a um novo formato de biblioteca, esta, voltada ao seu público, como foco principal, e não, apenas, as suas obras informacionais (OLIVEIRA, 2019, p. 30).

Zaninelli e Santos Neto (2017, p. 2636) enfatizam que as bibliotecas “[...] devem aprender a atuar neste ambiente cada vez mais mutável, adequando seus serviços às novas necessidades dos usuários" de tal forma que possam contribuir para o crescimento da sociedade.

Esse desenvolvimento conceitual também aconteceu com as bibliotecas escolares. No Brasil, as primeiras bibliotecas escolares surgem em conventos jesuíticos, no século XVI, e seu objetivo era auxiliar no processo de catequização dos índios. Nos séculos seguintes, ainda que tenha havido um enfraquecimento das ordens religiosas, o cunho religioso ainda perpassava a função da biblioteca escolar (CAMPELLO, 2015).

Entretanto, no final do século XIX, a concepção tradicional de ensino se vê enfraquecida, diante de novos estudos e linhas de investigação em torno do aprendizado. Neste momento, surge o movimento escolanovista. A Escola Nova propõe uma educação na qual o aluno se torna o centro do processo de ensino-aprendizagem, promovendo a sua autonomia, criatividade e participação na resolução de problemas (SILVA, 2012).

Já no século XX, a biblioteca escolar começa a ser reconhecida como recurso fundamental à aprendizagem graças às reformas de ensino pautadas no movimento da Escola Nova, com a publicação do Manifesto dos Pioneiros da Educação Nova, em 1932 (AZEVEDO, 1984). Este manifesto "representou um dos mais significativos e propositivos 
movimentos nacionais em prol da implantação do sistema de educação pública" (SILVA, 2012, p. 4) e impactou diretamente na regulamentação de políticas educacionais que impulsionaram o sistema educacional.

Mas, é somente em meados do fim do século XX que se inicia uma movimentação de políticas públicas que impulsionam o desenvolvimento das bibliotecas escolares, como por exemplo, a Lei de Diretrizes e Bases da Educação Nacional (BRASIL, 1996), os Parâmetros Curriculares Nacionais (BRASIL, 1997) e a Lei nº 12.244 (BRASIL, 2010).

A Lei $\mathrm{n}^{\circ}$ 12.244, de 24 de maio de 2010, determina que todas as instituições públicas e privadas do país, em todos os níveis de ensino, contem com uma biblioteca. Isso deveria ser efetivado dentro do prazo máximo de dez anos (BRASIL, 2010). Entretanto, o levantamento do Censo da Educação Básica (BRASIL, 2020), em 2019, constatou que bibliotecas escolares ou espaços de leitura estão presentes em apenas $52 \%$ do total das instituições escolares do Brasil. Para além do número, aquém do esperado, de bibliotecas escolares implementadas no Brasil, Campello et al. (2012), adicionam um diagnóstico pouco otimista sobre suas condições e situações reais. Afirmam que

[...] muitos dos textos ressaltam a importância da biblioteca escolar e, ao mesmo tempo, chamam atenção para suas fragilidades e deficiências, exortando os responsáveis a tomar providências para mudar a situação (CAMPELLO et al., 2012, p. 2).

Nas últimas três décadas ocorreram mudanças significativas na forma como alunos e professores têm acesso aos conteúdos e ao conhecimento. "A mídia digital - Internet, telefonia móvel, jogos de computador, televisão interativa - hoje é um aspecto indispensável no tempo de lazer das crianças e dos jovens" (BUCKINGHAM, 2010, p. 38) bem como em seus processos de interação social, ensino-aprendizagem e aquisição de informações. Essa 'cultura digital' demanda um olhar crítico para o uso de mídias na educação, incluindo aqui o papel das bibliotecas.

A cultura digital não deve ser entendida como um movimento totalizador, que equaliza todas as experiências e vivências em uma "totalidade" (LEVY, 1999). Pode ser vista como uma série de práticas e ações emergentes, diversas, de grupos que têm suas relações e organização cada vez mais mediadas pelas redes e pelas novas mídias. Nesse sentido, a cultura digital pode ser entendida como: 
Reunindo ciência e cultura, antes separadas pela dinâmica das sociedades industriais, centrada na digitalização crescente de toda a produção simbólica da humanidade, forjada na elação ambivalente entre o espaço e o ciberespaço, na alta velocidade das redes informacionais, no ideal de interatividade e de liberdade recombinante, nas práticas de simulação, na obra inacabada e em inteligências coletivas, a cultura digital é uma realidade de uma mudança de era. Como toda mudança, seu sentido está em disputa, sua aparência caótica não pode esconder seu sistema, mas seus processos, cada vez mais auto-organizados e emergentes, horizontais, formados como descontinuidades articuladas, podem ser assumidos pelas comunidades locais, em seu caminho de virtualização, para ampliar sua fala, seus costumes e seus interesses. A cultura digital é a cultura da contemporaneidade (SILVEIRA, 2007, p. 1-2).

O conceito de "novas mídias" é essencial para o desenvolvimento de uma cultura de produção e disseminação de conhecimento e redes. Manovich (2001) nomeia de "novas mídias" aquelas que são computáveis. As mídias contemporâneas se transformam em dados, em software, que podem ser manipulados por computadores, e por consequência, abrem caminhos para práticas culturais distintas das que eram possíveis com as 'velhas' mídias. Essas “novas mídias" são essenciais para a emergência de práticas conhecidas da cultura digital, como a proliferação do número de autores e criadores de conteúdo, a recombinação e o remix (LEMOS, 2005).

No contexto da cultura digital, a biblioteca se reforça não só como um espaço de leitura, mas, sim, como um espaço de "diálogo permanente com o instituído, produzindo-se, a partir daí, novos produtos, novas culturas e novos conhecimentos" (PRETTO, 2010). Essa perspectiva reforça, portanto, uma concepção de biblioteca como espaço de construção do conhecimento, que em tempos de cultura digital deve investigar, de forma crítica, o desafio das novas mídias, com um propósito pedagógico alinhado ao projeto da instituição na qual está inserida.

\section{Incorporando os conceitos}

Diversas vertentes têm surgido em processos de inovação da biblioteca escolar. Nesse trabalho, partindo da perspectiva delineada acima sobre cultura digital e novas mídias, apontaremos três que têm potencial de diálogo com o espaço da biblioteca. São alvo desse tudo: a biblioteca como centro de recursos (CR; ou resource center), como espaço maker, e como hackerspace.

Com toda a mudança de perspectiva sobre o que é uma biblioteca escolar, "[...] muitas delas têm alterado sua nomenclatura, visto que o termo "biblioteca" não atende a totalidade de 
serviços e produtos" (ZANINELLI; SANTOS NETO, 2017, p. 40). Diversas bibliotecas escolares já incorporam uma diversidade de práticas e recursos que extrapolam perspectivas tradicionais, como por exemplo, espaços de criação com ferramentas (tintas, recicláveis, sucata); uma organização espacial que promove maior interação com o uso de dispositivos como computadores, máquinas de impressão 3D e óculos de realidade virtual; bem como promovem oficinas, treinamentos em uso de software e projetos de leitura. Muitas bibliotecas tornaram-se um espaço de aprendizagem expandido para a comunidade e promovem ações que contribuem significativamente com a produção de conhecimento. Dentre essas nomenclaturas, aparece o termo Centro de Recursos, que busca romper com a ideia de um acervo de livros, e engloba um espaço colaborativo, de exploração, que contempla além dos materiais bibliográficos, recursos audiovisuais, ferramentas, máquinas, e que se integra ao planejamento pedagógico da instituição em que se insere (GASQUE, 2013).

Os Centros de Recursos são bibliotecas que passaram por um processo de reestruturação em seu conceito em consonância com um trabalho de conscientização na instituição para compreender o novo perfil de biblioteca adotado (SANTOS; CANDIDO, 2019). Segundo Santos e Candido (2019, p. 120), o CR tem “[...] finalidade primária de estimular a colaboração, a exploração e o fascínio", contribuindo com uma educação emancipadora, autônoma e criativa. Além disso, o espaço oferece uma série de recursos tecnológicos e atividades com base no conceito STEAM: ciências, tecnologia, engenharia, artes e matemática (aqui, tomando como exemplo, CASA THOMAS JEFFERSON, 2020).

Concomitantemente, uma outra vertente, conhecida como maker, também tem se difundido e influenciado a concepção de bibliotecas escolares. Este baseia-se na necessidade humana de estar envolvido com a construção e criação de coisas, que desperta a curiosidade, a criatividade, o movimento de tentativa e erro, a busca por soluções e, uma característica fundamental, a conexão entre pessoas (DOUGHERTY, 2012). Na escola, o maker se consolidou por meio de diferentes manifestações conhecidas como espaços maker ou makerspaces. Hatch (2014, p. 13) conceitua esse espaço como "[...] um centro ou um espaço de trabalho onde pessoas afins encontram-se para criar coisas”. Mas, tratando-se do ambiente escolar, esses espaços são "[...] usados para as mais diversas atividades, cursos e serviços relacionados à informação, cultura e desenvolvimento de habilidades de pesquisa e uso de novas tecnologias" (MACEDO; SANTOS, 2016, p. 72). 
Um dos modelos de implementação desses espaços é conhecido como FabLabs. Apesar de tratar-se de um laboratório de prototipagem mais técnica (PINTO et al., 2018) sua essência principal também se constitui no movimento mão-na-massa. Segundo Pinto e colegas (2018), no mundo há 631 FabLabs, sendo que desses, 17 ficam no Brasil e, em sua grande maioria, dentro de universidades. Os "[...] FabLabs estão sendo cada vez mais adotados por escolas como plataformas baseadas em projetos mão na massa da educação" (PINTO et al., 2018). Gomes et al. (2017) exemplificam um caso ao relatar sobre a implementação de uma disciplina denominada "Laboratório Maker" no Colégio de Aplicação da Universidade do Vale do Itajaí (CAU) com o intuito de desenvolver projetos mão na massa combinados com uma série de recursos e ferramentas, com organização do espaço adequada e um planejamento pedagógico coerente com a cultura maker.

Sobre bibliotecas escolares, Colegrove (2013) traz uma importante discussão sobre o potencial e impactos de makerspaces em bibliotecas. Segundo o autor, nos Estados Unidos, tem ocorrido um forte movimento de integração entre esses dois espaços, que contribui com a renovação do conceito de biblioteca. Essa mudança ocorre em todos os tipos de bibliotecas, sejam elas públicas, universitárias, comunitárias ou escolares.

Outra vertente é a criação de hackerspaces, que são espaços de experimentação colaborativos pautados na cultura e ética hacker. A ética hacker surge no século passado com o advento da computação, quando jovens estudantes dão início à uma movimentação em laboratórios universitários, garagens, oficinas, para criar soluções e novos projetos tecnológicos (PRETTO, 2010). Desde então, inicia-se essa construção da cultura hacker pautada em alguns princípios fundamentais: a paixão, a liberdade, o compartilhamento de conhecimento, ter uma postura ativa, ser responsável com a comunidade e ser criativo, isto é, usar aquilo que sabe em prol do desenvolvimento e melhoramento de algo (AGUADO, 2016, p. 9).

Ao olhar algumas dessas características, como a conexão interpessoal, compartilhamento de ideias, desenvolvimento cultural, tecnológico e democratização da informação sob uma perspectiva pedagógica, é possível perceber que uma concepção pedagógica permeia esses espaços. Assim, torna-se viável, através de uma "ética hacker" (PRETTO, 2010), um alinhamento dessa concepção com os espaços de educação formal,

\footnotetext{
1 "O CAU é um ambiente educacional de articulação entre o ensino básico e o superior, que incentiva o ensino, a pesquisa e a extensão, propiciando a formação de profissionais e o desenvolvimento de materiais didáticospedagógicos" (GOMES et. al, 2017, p. 304-305).
} 
através de novos olhares para a prática docente, com a liderança dos professores (PRETTO, 2010). Isso ocorre não exclusivamente pela implementação de tecnologia, mas, sim, na forma como o seu uso:

[...] pode colaborar para uma mudança no modo como as pessoas se relacionam no coletivo escolar, no modo como produzem e compartilham conteúdo, se tornam mais curiosas acerca do funcionamento do mundo e das coisas que o constroem, desafiam falsas hierarquias impostas socialmente, se apropriam dos computadores e das tecnologias, para além do uso ferramental (CANDIAN; BRUNO, 2020, p. 14).

Ou seja, um compilado de todas essas características, a ética hacker, bem como a cultura maker, aliadas ao uso crítico das tecnologias, a disponibilização de recursos e ferramentas, um espaço adequado e uma equipe que entenda efetivamente esse conceito, podem contribuir efetivamente para uma atuação mais horizontal entre docentes e alunos e novas concepções acerca de bibliotecas escolares.

Seguindo o exposto, neste estudo buscamos identificar, através de uma revisão sistemática da literatura, como está sendo tratado o tema da inovação em bibliotecas escolares brasileiras com base nessas três vertentes: makerspaces, hackerspaces e Centro de Recursos.

\section{Metodologia}

A revisão sistemática de literatura é um modelo de investigação que visa analisar as contribuições literárias já existentes sobre determinada área, por meio de etapas bem estruturadas e claras.

\footnotetext{
A revisão sistemática caracteriza-se [...] por empregar uma metodologia de pesquisa com rigor científico e de grande transparência, cujo objetivo visa minimizar o enviesamento da literatura [...] Assim, é basilar o objetivo de estruturar todos os procedimentos de forma a garantir a qualidade das fontes, logo pela definição de uma equação de pesquisa, de critérios de inclusão e exclusão e de todas as normas que julguem convenientes para o caso (RAMOS; FARIA; FARIA, 2014, p. 22).
}

É importante salientar que a credibilidade da pesquisa está atrelada à possibilidade de replicação dos procedimentos por outros indivíduos e, por isso, é necessário apresentar todos os processos de forma transparente e sistemática. Ramos, Faria e Faria (2014) propõem um protocolo de procedimentos para nortear a realização de uma revisão de literatura, no qual este trabalho foi pautado. Constam nesse protocolo a definição de objetivos, equações de 
pesquisa $^{2}$, o âmbito $^{3}$, critérios de inclusão e exclusão, critérios de validade metodológicas, os resultados e o tratamento de dados.

\section{Objetivos e Perguntas}

Este trabalho tem por objetivo responder às seguintes questões. Primeiro, quais são as tendências de inovação envolvendo novas mídias nas bibliotecas escolares do Brasil? Segundo, de que maneira as escolas estão incorporando conceitos associados a makerspaces, hackerspaces e resource centers para ressignificar a função da biblioteca escolar?

\section{Equações de Pesquisa}

Nesta pesquisa, utilizou-se 9 termos de busca visando responder às questões elencadas acima: "Escola" e "centro de recursos"; "Escola" e "makerspace"; "Escola" e "hackerspace"; "Escola" e "resource center"; "Biblioteca" e "inovação"; "Biblioteca" e "makerspace"; "Biblioteca" e "hackerspace"; "Biblioteca" e "resource center" e "Biblioteca" e "centro de recursos".

\section{Âmbito da Pesquisa}

Foram determinadas 11 bases de dados como fonte de referências para a revisão sistemática (Quadro 1).

Quadro 1 - Base de Dados (continua...)

\begin{tabular}{|c|c|c|}
\hline Base de Dados (Nome) & Sigla & Link de Acesso \\
\hline $\begin{array}{l}\text { Directory of Open Access } \\
\text { Journals }\end{array}$ & DOAJ & https://doaj.org/ \\
\hline $\begin{array}{l}\text { Repositórios Científicos } \\
\text { de Acesso Aberto de } \\
\text { Portugal }\end{array}$ & RCAAP & https://www.rcaap.pt/ \\
\hline Scielo & - & https://scielo.org/ \\
\hline Edubase & - & http://portal.edubase.modalbox.com.br \\
\hline Educ@ _ _ n & - & http://educa.fcc.org.br/ \\
\hline Revista Brasileira de & RBIE & https://www.br-ie.org/pub/index.php/rbie \\
\hline
\end{tabular}

Bibl. Esc. em R., Ribeirão Preto, v. 8, n. 1, p. 42-63, 2022. 
Tendências de inovação em bibliotecas escolares: vertentes emergentes para ressignificar esses espaços

\begin{tabular}{|l|c|l|}
\hline Informática na Educação & & \\
\hline $\begin{array}{l}\text { Simpósio Brasileiro de } \\
\text { Informática na Educação }\end{array}$ & SBIE & https://www.br-ie.org/pub/index.php/sbie \\
\hline $\begin{array}{l}\text { Anais do Workshop de } \\
\text { Informática na Escola }\end{array}$ & WIE & https://www.br-ie.org/pub/index.php/wie \\
\hline $\begin{array}{l}\text { Anais dos Workshops do } \\
\text { Congresso Brasileiro de } \\
\text { Informática na Educação }\end{array}$ & WCBIE & https://www.br-ie.org/pub/index.php/wcbie \\
\hline Biblioteca da Anped & - & $\underline{\text { http://www.anped.org.br/biblioteca }}$ \\
\hline $\begin{array}{l}\text { Base de Dados em } \\
\text { Ciência da Informação }\end{array}$ & BRAPCI & www.brapci.inf.br \\
\hline
\end{tabular}

Fonte: Dados da Pesquisa (2020)

Para contemplar referências mais específicas da área de biblioteconomia, a BRAPCI foi sugerida depois de uma consulta à uma bibliotecária formada e à assessoria de informações da Biblioteca Central da Universidade [OMITIDO]. As demais bases de dados foram selecionadas, primeiro, por se tratarem de repositórios de artigos em acesso aberto (ALBAGLI; CLINIO; RAYCHTOCK, 2014); segundo, porque concentram grande quantidade de periódicos em língua portuguesa com enfoque na área de educação e, também, em informática e educação.

\section{Critérios de Inclusão e Exclusão}

No intuito de delimitar o campo de pesquisa, foram determinados os seguintes critérios de inclusão: (1) trabalhos publicados entre os anos 2000 e 2020; (2) trabalhos em português; e (3) artigos, publicações em conferências ou resumos expandidos revisados por pares, além de teses e dissertações.

Quanto aos critérios de exclusão, foram eliminados os trabalhos publicados fora dos anos delimitados (2000-2020), publicações em outros idiomas que não o português; aqueles que não discorreram sobre tecnologia e novas mídias em escolas e bibliotecas escolares; aqueles que desenvolveram sua pesquisa em outros tipos de biblioteca que não a escolar e, por fim, tipos de publicação que não se enquadram na delimitação do universo da pesquisa.

Devido às particularidades das bases de dados, o refinamento da busca variou de acordo com as ferramentas de filtro disponíveis em cada uma delas. Isto posto, é importante ressaltar que a plataforma DOAJ e a biblioteca da Anped não disponibilizam recursos de filtro. Os resultados apresentados nessas duas bases de dados são referentes apenas aos termos de busca, isto é, não foram utilizados nenhum tipo de filtro para refinar a pesquisa. As buscas 
no RCAAP e Scielo foram realizadas utilizando os filtros: ano (2000 - 2020) e idioma (português). Por fim, na BRAPCI utilizou-se apenas o filtro data de publicação (2000 - 2020).

\section{Resultados}

As bases da Anped, Edubase, Educ@, RBIE, SBIE, WIE e WCBIE não retornaram resultados de pesquisa para nenhum termo de busca. Portanto, o universo da pesquisa contemplou apenas os resultados de 4 bases de dados: DOAJ, RCAAP, Scielo e BRAPCI. A Tabela 2 aponta os resultados de pesquisa em cada termo de busca e em cada plataforma.

Tabela 1 - Resultados de Pesquisa (continua...)

\begin{tabular}{lccccc}
\hline \multicolumn{1}{c}{ Termo de Busca } & DOAJ & RCAAP & Scielo & BRAPCI & Total \\
\hline Escola e "centro de recursos" & 18 & 0 & 1 & 1 & $\mathbf{2 0}$ \\
\hline $\begin{array}{l}\text { Escola e makerspace (alteração } \\
\text { para makerspace }\end{array}$ & 52 & 3 & 0 & 5 & $\mathbf{6 0}$ \\
\hline $\begin{array}{l}\text { Escola e hackerspace (alteração } \\
\text { para hackerspace }\end{array}$ & 6 & 0 & 0 & 3 & $\mathbf{9}$ \\
\hline Escola e "resource center" & 0 & 0 & 0 & 1 & $\mathbf{1}$ \\
\hline Biblioteca e inovação & 40 & 0 & 10 & 88 & $\mathbf{1 3 8}$ \\
\hline Biblioteca e makerspace & 1 & $4^{6}$ & 70 & 4 & $\mathbf{9}$ \\
\hline Biblioteca e hackerspace & 0 & 0 & 0 & 0 & $\mathbf{0}$ \\
\hline Biblioteca e "resource center" & 0 & 0 & 0 & 5 & $\mathbf{5}$ \\
\hline Biblioteca e "centro de recursos" & 10 & 2 & 0 & 5 & $\mathbf{1 7}$ \\
\hline Total & $\mathbf{1 2 7}$ & $\mathbf{9}$ & $\mathbf{1 1}$ & $\mathbf{1 1 2}$ & $\mathbf{2 5 9}$ \\
\hline
\end{tabular}

Fonte: Dados da Pesquisa (2020)

O resultado de busca de todas as plataformas totalizou 259 publicações, entretanto, após unificação dos trabalhos duplicados, o total foi de 204 itens. Foram exportados para o Zotero $^{8}$, uma plataforma em software livre para referências bibliográficas, e partiu-se para o

\footnotetext{
${ }^{4}$ Como os termos "escola" e "makerspace" não apresentaram resultados, foi feita a alteração do termo de busca apenas para "makerspace" em todas as bases de dados.

5 Da mesma forma, os termos "escola" e "hackerspace" juntos não retornaram nenhum resultado de busca. Portanto, alterou-se o termo para apenas "hackerspace" em todas as bases de dados.

${ }^{6}$ A busca avançada do RCAAP não apresentou resultados. Mas, a busca simples, retornou 4 publicações, em português e entre os anos 2000 - 2020.

${ }^{7}$ A busca avançada do RCAAP não apresentou resultados. Mas, a busca simples, retornou 4 publicações, em português e entre os anos 2000 - 2020.

${ }^{8}$ Os dados dessa pesquisa encontram-se abertamente disponíveis para uso e verificação em:
} 
processo de análise dos trabalhos. Para facilitar a seleção dos artigos, foram determinadas algumas tags (descritores) como critérios de organização e transparência de análise (Quadro 2), que podem ser utilizadas para filtragem de dados, no grupo criado no sistema Zotero.

Quadro 2 - Organização das tags para seleção

\begin{tabular}{|ll|}
\hline \multicolumn{1}{|c|}{ Tag } & \multicolumn{1}{c|}{ Definição } \\
\hline Não - Título & Eliminados pelo título do trabalho. \\
\hline Não- - Resumo & Eliminados depois da leitura do resumo da publicação. \\
\hline Não- Texto & Eliminados depois da leitura íntegra do texto. \\
\hline Não - Idioma & Eliminados por estar em outro idioma que não o português. \\
\hline Sim & Trabalhos incluídos na análise. \\
\hline & \multicolumn{1}{c|}{ Fonte: Dados da pesquisa (2020) } \\
\hline
\end{tabular}

Todos os trabalhos duplicados, isto é, que apareceram como resultado de busca em mais de um termo e/ou em mais de uma plataforma, foram unificados restando assim 204 itens únicos. Destes, 119 publicações foram excluídas na leitura dos títulos por não contemplarem a área de estudo. Outros 46 trabalhos foram eliminados por desenvolverem seus diálogos em outro idioma e 28 trabalhos foram excluídos após leitura de seus resumos. Por fim, 3 trabalhos foram excluídos após leitura integral do texto. O processo foi objeto de revisão por pares, isto é, para a validação da lista houve uma avaliação de duas pessoas. Para que os textos entrassem em qualquer categoria, incluso ou eliminado, foi necessário a concordância de ambos. Este é um dos processos que norteiam a confiabilidade da pesquisa científica (NASSI-CALÒ, 2015).

Dessa forma, este trabalho será pautado na análise de 8 publicações, sendo 7 artigos e 1 dissertação. As informações sobre cada publicação serão descritas no quadro abaixo.

Quadro 3 - Publicações Analisadas (continua...)

\begin{tabular}{|c|c|c|c|}
\hline & Título & Revista & Ano \\
\hline 1 & $\begin{array}{l}\text { A biblioteca do futuro: um olhar em } \\
\text { direção ao presente }\end{array}$ & Informação \& Informação & 2019 \\
\hline 2 & $\begin{array}{l}\text { Biblioteca escolar com makerspace: } \\
\text { um estudo de caso na Biblioteca } \\
\text { Abraham Lincoln }\end{array}$ & $\begin{array}{l}\text { Revista Brasileira de } \\
\text { Biblioteconomia e } \\
\text { Documentação }\end{array}$ & 2017 \\
\hline 3 & $\begin{array}{l}\text { Bibliotecas como makerspace: } \\
\text { oportunidades de implementação a partir } \\
\text { de um caso prático }\end{array}$ & $\begin{array}{c}\text { Ciência da Informação em } \\
\text { Revista }\end{array}$ & 2019 \\
\hline 4 & $\begin{array}{l}\text { Centro de Recursos de Aprendizagem: } \\
\text { biblioteca escolar para o século XXI }\end{array}$ & $\begin{array}{c}\text { Revista Digital de } \\
\text { Biblioteconomia e Ciência da } \\
\text { Informação }\end{array}$ & 2013 \\
\hline
\end{tabular}

https://www.zotero.org/groups/[OMITIDO PARA AVALIAÇÃO]

Bibl. Esc. em R., Ribeirão Preto, v. 8, n. 1, p. 42-63, 2022. 
5 Competência leitora nas bibliotecas Em Questão escolares

6 Inovação em bibliotecas: considerações sobre a disponibilização de serviço de impressão 3D

7 Makerspace em bibliotecas escolares:

Revista Brasileira de 2017 Biblioteconomia e Documentação uma análise bibliométrica

8 Práticas inovadoras nas bibliotecas escolares em Florianópolis: empreendedorismo cultural em foco Fonte: Dados da Pesquisa (2020)

Também foram definidos alguns critérios gerais de análise dos textos, indicados por tags descritivas. São eles: nível de ensino, contexto formal ou não-formal, o tipo de estudo e quais métodos foram utilizados. Em cada categoria, acrescentou-se a classe "Não se aplica" (NA) para casos nos quais não era possível identificar a informação requerida. É importante ressaltar que uma mesma publicação pode se encaixar em mais de uma subcategoria de análise, apresentada na Tabela 2 e disponível para investigação na plataforma Zotero.

Tabela 2 - Categorias de análise (continua...)

\section{Categorias de Análise}

Quantidade de Publicações

\section{Nível de Ensino}

\begin{tabular}{cc}
\hline Educação Infantil (EI) & 1 \\
\hline Ensino Fundamental 1 (EF1) & 2 \\
\hline Ensino Fundamental 2 (EF2) & 2 \\
\hline Ensino Médio (EM) & 6 \\
\hline Não se Aplica (NA) & 6 \\
\hline Contexto & 0 \\
\hline Formal & 2 \\
\hline Não-formal & 1 \\
\hline Não se Aplica (NA) & 0 \\
\hline Tipo de Estudo & 0 \\
\hline Teórico & \\
\hline Crítico & \\
\hline Metodológico & \\
\hline
\end{tabular}


Tendências de inovação em bibliotecas escolares: vertentes emergentes para ressignificar esses espaços

\begin{tabular}{ll}
\hline Intervenção & 0 \\
\hline Empírico & 4 \\
\hline Avaliação & 1 \\
\hline Revisão & 3 \\
\hline Descritivo & 1 \\
\hline Métodos & 3 \\
\hline Quantitativo & 2 \\
\hline Qualitativo & 2 \\
\hline Misto & 1 \\
\hline Não se Aplica (NA) & \\
\hline
\end{tabular}

Fonte: Dados da Pesquisa (2020)

\section{Discussão}

Os trabalhos selecionados foram organizados de acordo com suas contribuições para as perguntas deste estudo, isto é, após a leitura integral de cada produção determinou-se a qual pergunta o texto melhor contribuiu. Utiliza-se a nomenclatura P1 para a pergunta de número 1: Quais são as tendências de inovação envolvendo novas mídias nas bibliotecas escolares do Brasil?; e P2 para a pergunta de número 2: De que maneira as escolas estão incorporando conceitos associados a makerspaces, hackerspaces e resource centers para ressignificar a função da biblioteca escolar?. Essa divisão foi ilustrada no Quadro 4.

Quadro 4 - Relação texto x perguntas de pesquisa

\begin{tabular}{|c|c|c|c|c|c|c|c|c|} 
Trabalho & $\mathbf{1}$ & $\mathbf{2}$ & $\mathbf{3}$ & $\mathbf{4}$ & $\mathbf{5}$ & $\mathbf{6}$ & $\mathbf{7}$ & $\mathbf{8}$ \\
\hline Pergunta & $\mathrm{P} 1 / \mathrm{P} 2$ & $\mathrm{P} 1 / \mathrm{P} 2$ & $\mathrm{P} 1 / \mathrm{P} 2$ & $\mathrm{P} 1 / \mathrm{P} 2$ & $\mathrm{P} 1$ & $\mathrm{P} 1$ & $\mathrm{P} 1 / \mathrm{P} 2$ & $\mathrm{P} 1$ \\
\hline
\end{tabular}

\section{Pergunta 1. Quais são as tendências de inovação envolvendo novas mídias nas bibliotecas escolares do Brasil?}

Nos trabalhos selecionados há um consenso de que a biblioteca, entendida como um espaço unicamente de armazenamento de livros ou informação, não contempla mais as necessidades da sociedade atual. Submersos na era das novas mídias, sabe-se que é uma necessidade emergente que esses espaços busquem manter-se ativos dentro das perspectivas 
de inovação. Jesus (2019, p. 38) afirma que “[...] a biblioteca está se projetando como um local de convivência, de construção de conhecimento compartilhado, ao contrário do papel que ocupava antigamente de organizar e armazenar o conhecimento". Nas bibliotecas escolares, esse movimento não é diferente. Os alunos são "sujeitos já inseridos no contexto tecnológico e em contato direto e frequente com os diversos dispositivos de comunicação" (ZANINELLI; SANTOS NETO, 2017, p. 37), fazendo com que a responsabilidade e a necessidade de alinhamento com práticas inovadoras seja ainda mais indispensável.

Nesse sentido, umas das tendências de inovação que têm se mostrado promissoras no Brasil é a implementação dos makerspaces nas bibliotecas escolares. Jesus e Cunha (2019, p. 316) ressaltam a influência da web no desenvolvimento desses espaços colaborativos e, durante a discussão sobre uma das vertentes de biblioteca participativa, os autores apontam que "uma segunda característica da biblioteca participatória seria o desenvolvimento dos espaços de criação ou colaboração, tais como os makerspaces". Afirmam ainda que "a biblioteca, como local físico, deve dar valor a espaços colaborativos que propiciem um ambiente de desenvolvimento coletivo, tais como makerspaces e outros tipos de laboratórios ou salas" (JESUS; CUNHA, 2019, p. 323). Zaninelli e Santos Neto (2017) também trazem a discussão sobre makerspaces como uma proposta de inovação para as bibliotecas escolares:

\footnotetext{
Nesse contexto, tendo as bibliotecas escolares a necessidade de se manter ativas na sociedade, a inovação tornou-se um processo necessário. Portanto, seus gestores ou dirigentes estão desenvolvendo ações e estratégias que vão ao encontro das necessidades dos nativos digitais. Entre elas, destaca-se a inserção de makerspaces nesses ambientes (ZANINELLI; SANTOS NETO, 2017, p. 42).
}

Além disso, abordam a flexibilização do espaço físico como fundamental ao processo de implementação. Segundo Zaninelli e Santos Neto (2017, p. 40), "não é atrativo a essa geração um espaço frio, desconfortável, no qual se exige silêncio e lida-se com regras inflexíveis constantemente". O espaço físico é essencial para a perspectiva de um espaço colaborativo, e deve ser adequado.

Santos e Candido trazem uma reflexão importante quando incorporam ao significado dos espaços maker um objetivo educacional, quando aliados ao espaço da biblioteca.

O modelo mental de biblioteca mudou esse novo conceito, que traz uma definição mais pedagógica. Esse novo modelo faz com que a visão de makerspace como um todo dentro da biblioteca seja diferente, ou seja, a biblioteca com o espaço do fazer passa a mensagem de que a forma de aprender mudou. A forma de aprender engloba muito mais do que livros, estudos ou computadores, possibilitando o aprendizado de maneiras diferentes e através da experimentação. (SANTOS; CANDIDO, 2019, p. 121) 
Ou seja, entende-se o makerspace e a biblioteca como espaços que se fortalecem, e que juntos contribuem para uma nova estrutura pedagógica e de ensino.

O estudo de Duarte e Spudeit (2018) mapeou, por meio de questionários, as práticas inovadoras em bibliotecas de Florianópolis. Ainda que a maioria dos projetos de inovação mencionados pelos entrevistados tenham mais relação com a literacia, houve uma menção sobre o espaço maker como um produto e/ou serviço inovador. Posteriormente, os próprios autores apresentam o makerspace como proposta de ação inovadora em bibliotecas escolares. Segundo eles, "uma ótima oportunidade para empreender e experimentar, que pode contribuir para desenvolver a aprendizagem por meio da recreação é criar espaços de makerspace" (p. 120). Ademais, Duarte e Spudeit apresentam como outra estratégia a inserção de videogames e recursos audiovisuais na biblioteca, não somente como ferramenta recreativa mas reconhecendo seu potencial pedagógico e desenvolvimento cultural.

Vieira (2017) também traz a perspectiva de espaço maker em bibliotecas com foco na implementação de impressoras 3D. Existe, de acordo com o autor, uma relação benéfica para a biblioteca e para os usuários ao disponibilizar essa ferramenta dentro dos espaços informacionais, já que promove uma relação pedagógica no desenvolvimento de protótipos, habilidades com software de modelagem, planejamento, livre expressão artística e criativa. $\mathrm{O}$ autor pontua que:

a questão chave que deve ser observada é a criação de uma cultura de inovação que tenha propósito e metas claras para serem declaradas no projeto para estabelecimento de um espaço maker que possua impressora 3D numa biblioteca (VIEIRA, 2017, p. 14).

Além de uma perspectiva de inovação, a implementação do espaço maker fortalece a relação pedagógica de uma biblioteca escolar. Essa comunhão de espaços promove um processo de ensino-aprendizagem mais dinâmico, criativo, colaborativo e significativo. Jesus (2019) afirma que

o makerspace se encaixa na concepção da biblioteca escolar (BE) na medida em que serve como um apoio direto ao processo de ensino-aprendizado, podendo ser usado como um espaço didático-pedagógico de potencial ainda não explorado em sua totalidade (JESUS, 2019, p. 38).

Outra tendência de inovação em bibliotecas discutida nos trabalhos analisados é a biblioteca como Centro de Recursos de Aprendizagem (CRA). Ainda que converse com a concepção de um makerspace, Gasque (2013) e Gasque e Silvestre (2017) mostram que o CRA enfatiza compor todo o planejamento pedagógico da instituição no qual se insere, como instrumento de desenvolvimento do currículo: 
O paradigma de integração pedagógica requer compreender a biblioteca escolar atuante como Centro de Recursos de Aprendizagem, isto é, como instituição que organiza materiais bibliográficos, audiovisuais e outros meios e os coloca à disposição da comunidade educacional, constituindo-se parte integral do sistema educativo e participando de seus objetivos, metas e fins (GASQUE, 2013, p. 140).

Gasque e Silvestre (2017) apresenta um quadro comparativo com as características de uma biblioteca escolar tradicional e um Centro de Recurso de Aprendizagem, que permite enxergar um panorama mais claro sobre suas principais contribuições:

Figura 1 - Paradigmas da biblioteca escolar

\begin{tabular}{|c|c|}
\hline Biblioteca escolar tradicional - BE & Centro de Recursos de Aprendizagem - CRA \\
\hline $\begin{array}{l}\text { - } \text { - Faradigma da preservação. } \\
\text { - Centrado na transmissão de } \\
\text { conhecimento. } \\
\text { - Armazenamento de livros. } \\
\text { - Animação da leitura. }\end{array}$ & $\begin{array}{l}\text { - } \text { Paradigma da integração pedagógica. } \\
\text { - Espaços multiusos. } \\
\text { - } \text { - Centrado no letramento informacional. } \\
\text { - Acesso aos diferentes pontos de vistas dos } \\
\text { conteúdos. } \\
\text { - Instrumento de desenvolvimento do curriculo. } \\
\text { - Fomento à leitura e à pesquisa cientifica. } \\
\text { - Caráter pedagógico e cultural. } \\
\text { - Estrutura adequada, Layout funcional. } \\
\text { - Uso de TIC's. }\end{array}$ \\
\hline
\end{tabular}

Fonte: Gasque; Silvestre, 2017.

Além disso, Gasque e Silvestre (2017) abordam um argumento importante, e que se enquadra numa perspectiva geral dos espaços, no que diz respeito à flexibilidade do currículo. Para que o Centro de Recursos de Aprendizagem seja efetivo em sua proposta é fundamental que a instituição faça adequação do seu planejamento e de seu currículo com base nas demandas e possibilidades que esse espaço proporciona.

Vale destacar que os conceitos de makerspace, FabLabs e hackerspace, apesar de serem conceitos distintos, têm muitos pontos de convergência e caminham sob uma mesma perspectiva de inovação e, portanto, por vezes torna-se difícil de diferenciá-los. Normalmente, esses termos se enquadram na definição ou conceituação de espaços de criação colaborativos, ainda que existam suas especificações. Jesus (2019) aponta que

O que se pode propor com certeza é a ideia que cerca os espaços de criação como locais de reunião e compartilhamento, utilizando ferramentas tecnológicas para resolução de problemas do dia-a-dia ou educativos, propostos por uma equipe específica com objetivos que vão desde estimular a criatividade, resolução de problemas, criação de novas tecnologias ou ferramentas inovadoras, desenvolvimento de competências e reforço pedagógico em atividades extra-classe (JESUS, 2019, p. 48). 
Tendências de inovação em bibliotecas escolares: vertentes emergentes para ressignificar esses espaços

Sendo assim, de acordo com os textos as principais tendências de inovação envolvendo novas mídias em bibliotecas escolares no Brasil relacionam-se às concepções de espaço maker e Centro de Recursos de Aprendizagem. Ambos integrados ao processo pedagógico e pautados na inovação, uso de tecnologias, fomento à criatividade, democratização do ensino, compartilhamento de informações, desenvolvimento de projetos e promoção de habilidades artísticas, matemáticas, lógicas, sociais, científicas, dentre outras.

\section{Pergunta 2. De que maneira as escolas estão incorporando conceitos associados a makerspaces, hackerspaces e resource centers para ressignificar a função da biblioteca escolar?}

O público alvo das escolas são crianças e jovens que nascem "inseridos no contexto tecnológico e em contato direto e frequente com os diversos dispositivos de comunicação" (ZANINELLI; SANTOS NETO, 2017, p. 37). Apesar de ser uma generalização, nos leva a contemplar e avaliar quem são os usuários desses espaços e quais são as suas necessidades, em um cenário crescente de incorporação de novas mídias no contexto educacional, para tornar o serviço oferecido pelas escolas mais efetivo e adaptá-lo às exigências do perfil dos estudantes.

Dessa forma, é fundamental que as instituições saibam compreender de que forma podem contribuir com a educação e formação desses alunos, ao considerar as suas necessidades desenvolvidas com base numa vida cada vez mais imersa em novas tecnologias. É analisando esses aspectos, entendendo o seu público e repensando a forma de ensinar que se abre a oportunidade de incorporar práticas de inovação na estrutura educacional da biblioteca escolar.

Santos e Candido (2019) durante o relato sobre a implementação de um makerspace em uma biblioteca, na Casa Thomas Jefferson, levantam um segundo ponto importante: a necessidade de mudar a estrutura do modelo mental da instituição. Os conceitos de makerspace, hackerspace, a biblioteca como centro de recursos, ainda são pouco difundidos. Portanto, ao optar pela implementação de uma perspectiva como essa, faz-se necessário um processo de implementação que convença e instrua a comunidade escolar sobre um novo modelo de atuação. Dessa forma, há uma implementação gradual do conceito de cultura 
maker e da ética hacker que se incorpora o espaço de criação colaborativo como parte da cultura da escola.

[...] foram feitos trabalhos de conscientização para um novo perfil de biblioteca. [...] O seu principal objetivo era a mudança de modelo mental do que era a biblioteca, por isso essas atividades eram bem menores devido aos equipamentos que ainda não dispunham. Então, o trabalho de conscientização e de informação era feito também com todos os profissionais que trabalhavam na Casa Thomas Jefferson, e envolviam outras pessoas, tais como professores, alunos, pais, comunidade e bibliotecários (SANTOS; CANDIDO, 2019, p. 120).

Nesse mesmo sentido, Gasque (2013, p. 152) aborda a necessidade da "adoção de um currículo mais flexível, em que os professores estimulem a investigação científica ou que adotem, de maneira geral, os métodos de resolução de problemas”. E esse processo só acontece quando a integração entre currículo, gestores, docentes, bibliotecários, é efetiva. As mudanças na biblioteca devem estar alinhadas a uma mudança na cultura escolar, que ao menos acolha essas práticas colaborativas, afinal, é a biblioteca, como um espaço que contempla a todos, que irá fomentar essas práticas.

Outro ponto importante a ser considerado são os profissionais bibliotecários. Eles são, à primeira vista, a ponte direta entre a biblioteca e a incorporação de tendências inovadoras. Para isso, faz-se necessário que estes profissionais tenham uma familiaridade com novas mídias e, ainda, trabalhem dentro da perspectiva pedagógica, como um bibliotecário educador, juntamente com os docentes. É fundamental que haja pessoas que auxiliem esses profissionais de tal forma que contribua com a sua ação pedagógica de maneira eficiente e consistente (GASQUE; SILVESTRE, 2017).

\section{Conclusão}

Neste trabalho realizamos um mapeamento sistemático de literatura para mapear e analisar as tendências de inovação em bibliotecas escolares no Brasil. Além disso, buscou-se descobrir de que forma as escolas estão introduzindo os conceitos de makerspaces, hackerspaces e centro de recursos em suas bibliotecas. Inicialmente, para que se pudesse compreender o que são esses conceitos, foi feita uma breve revisão histórica sobre a biblioteca e a biblioteca escolar. Posteriormente, discutiu-se os espaços de criação colaborativos e suas definições. 
Tendências de inovação em bibliotecas escolares: vertentes emergentes para ressignificar esses espaços

A pesquisa indica que, ao discutir sobre inovação nas bibliotecas escolares, o espaço maker é a proposta mais apresentada como estratégia inovadora. Existe o reconhecimento do seu potencial criativo, pedagógico, social e inovador para os espaços escolares. Aponta-se que para uma implementação concreta dos makerspaces nas bibliotecas é necessário que a postura da instituição, professores, alunos e bibliotecários, se transformem e acompanhem essa mudança. Deve haver uma flexibilização do currículo, uma implementação gradual dos conceitos fundamentais por toda a comunidade escolar, além de uma formação profissional qualificada por parte dos bibliotecários - ou seja, para que tenha sucesso, faz parte um processo de transformação escolar (AMIEL; KUBOTA; WIVES, 2016).

Por conta da dificuldade de encontrar trabalhos que discutam essa temática no Brasil, observou-se que apesar de algumas instituições já contemplarem esses espaços de forma efetiva e de haver contribuições significativas com análises sobre esses espaços, esta ainda é uma área incipiente de investigação e não há um consenso sobre terminologias e conceitos, exceto o caso dos Fablabs, que são um laboratório de fabricação fundamentado por diretrizes criadas pelo Massachusetts Institute of Technology (MIT) (SANTOS; CÂNDIDO, 2019, p. $115)$.

Uma limitação desse trabalho é o enfoque somente em estudos escritos em português, assim delineado, para investigar práticas e investigações apropriadas para o contexto escolar brasileiro. Pesquisas sobre essa área estão sendo discutidas, em sua maioria, em países norteamericanos e europeus. Portanto, futuros estudos podem incluir literatura em outros idiomas, considerando e avaliando a pertinência das discussões e resultados para o Brasil. Além disso, buscar avaliar outros conceitos e modelos de inovação em biblioteca escolar, para além dos três elencados neste estudo.

As tendências aqui discutidas já são realidade em algumas bibliotecas escolares e servem como casos de exemplo para outras instituições. A perspectiva de um espaço colaborativo como um ambiente de fomento à inovação, criatividade, aprendizado, uso das novas mídias, pesquisa, desenvolvimento de projetos, compartilhamento e democratização da informação é fundamental para a educação. Além de todos os benefícios pedagógicos, torna a aprendizagem mais atrativa e significativa para toda a comunidade escolar. 


\section{Referências}

AGUADO, A. G. Hackeando a educação: desenvolvimento humano e justiça social na sociedade da informação. In: SIMPÓSIO NACIONAL ABCIBER, 9., 2016, São Paulo. Anais eletrônicos... São Paulo: PUC, 2016. Disponível em: https://abciber.org.br/anaiseletronicos/wpcontent/uploads/2016/trabalhos/hackeando_a_educacao_desenvolvimento_humano_e_justica _social_na_sociedade_da_informacao_alexandre_garcia_aguado.pdf. Acesso em: 2 dez. 2021.

ALBAGLI, S.; CLINIO, A.; RAYCHTOCK, S. Ciência aberta: correntes interpretativas e tipos de ação. Liinc em Revista, Brasília, v. 10, n. 2, 5 dez. 2014. Disponível em: http://revista.ibict.br/liinc/article/view/3593. Acesso em: 2 mar. 2021.

AMIEL, T.; KUBOTA, L. C.; WIVES, W. W. A systemic model for differentiating school technology integration. Research in Learning Technology, Oxfordshire, v. 24, 2016. Disponível em: https://journal.alt.ac.uk/index.php/rlt/article/view/1849. Acesso em: $1 \mathrm{dez}$. 2021.

AZEVEDO, F. O manifesto dos pioneiros da educação nova. Revista Brasileira de Estudos Pedagógicos, Brasília, v. 65, n. 150, p. 407-425, 1984.

BRASIL. Instituto Nacional de Estudos e Pesquisas Educacionais Anísio Teixeira (Inep). Censo da Educação Básica 2019: notas estatísticas. Brasília, 2020.

BRASIL. Lei $\mathbf{n}^{0} 12.244$ de 24 de maio de 2010. Dispõe sobre a universalização das bibliotecas nas instituições de ensino no país. Brasília: Congresso Nacional, [2010]. Disponível em: http://www.planalto.gov.br/ccivil_03/_ato2007-2010/2010/lei/112244.htm. Acesso em: 01 dez. 2021

BRASIL. Ministério de Educação e Cultura. LDB: Lei no 9394/96, de 20 de dezembro de 1996. Estabelece as diretrizes e bases da Educação Nacional. Brasília: MEC, 1996.

BRASIL. Secretaria de Educação Fundamental. Parâmetros Curriculares Nacionais: 1. a 4. séries. Brasília: MEC, 1997. 10 v.

BUCKINGHAM, D. Cultura digital, educação midiática e o lugar da escolarização. Educação \& Realidade, Porto Alegre, v. 35, n. 3, p. 37-58, set./dez. 2010.

CAMPELLO, B. S. Bibliotecas escolares e Biblioteconomia escolar no Brasil. Biblioteca Escolar em Revista, Ribeirão Preto, v. 4, n. 1, p. 1-25, ago. 2015.

CAMPELLO, B. S. et al. Situação das bibliotecas escolares no Brasil: o que sabemos? Biblioteca Escolar em Revista, Ribeirão Preto, v. 1, n. 1, p. 1-29, maio 2012.

CASA THOMAS JEFFERSON (Brasil). Resource center. 2020. Disponível em: https://thomas.org.br/servico/resource-center. Acesso em: 08 dez. 2020. 
CANDIAN, E. F.; BRUNO, A. R. Tecnologias digitais da informação e comunicação na educação e uma possível “educação hacker”. RPR, Rio Grande do Sul, n. 2, p. 8-23, maio/ago. 2020.

COLEGROVE, T. Editorial board thoughts: libraries as makerspace? Information Technology and Libraries, [Chicago], v. 32, 1st ed, p. 2-5, 2013.

DUARTE, T.; SPUDEIT, D. Práticas inovadoras nas bibliotecas escolares em Florianópolis: empreendedorismo cultural em foco. Perspectivas em Ciência da Informação, Belo Horizonte, v. 23, n. 3, p. 104-123, jul./set, 2018.

DOUGHERTY, Dale. The maker movement. Innovations: Technology, Governance, Globalization, Cambridge, v. 7, n. 3, p. 11-14, 2012.

GASQUE, K. C. G. D. Centro de recursos de aprendizagem: biblioteca escolar para o século XXI. RDBCI: Revista Digital de Biblioteconomia e Ciência da Informação, Campinas, v. 11, n. 1, p. 138-154, jan. 2013.

GASQUE, K. C. G. D.; SILVESTRE, F. D. M. Competência leitora nas bibliotecas escolares. Em Questão, Porto Alegre, v. 23, n. 3, p. 79-105, 21 ago. 2017.

GOMES, E. et al. A experiência de implantação de uma disciplina maker em uma escola de educação básica. In: WORKSHOP DE INFORMÁTICA NA ESCOLA, 23., 2017, Recife. Anais... Recife: SBC, 2017.

HATCH, Mark. The maker movement manifesto: rules for innovation in the new world of crafters, hackers, and tinkerers. [S. l.]: McGraw-Hill Education, 2014, 213 p.

JESUS, D. L. Makerspace em bibliotecas escolares: uma análise bibliométrica. 2019. 163 p. Dissertação (Mestrado em Gestão da Informação e Bibliotecas Escolares) - Universidade Aberta, Lisboa, 2019.

JESUS, D. L.; CUNHA, M. B. A biblioteca do futuro: um olhar em direção ao presente. Informação \& Informação, Londrina, v. 24, n. 3, p. 311-334, 2019.

LEMOS, A. Ciber-cultura-remix. In: Redes: criação e reconfiguração. Itaú Cultural, 2005. Disponível em: http://www.hrenatoh.net/curso/textos/andrelemos_remix.pdf.

LEVY, P. Cibercultura. São Paulo: Editora 34, 1999. p. 264.

MACEDO, P. A.; SANTOS, A. M. S. Design thinking para bibliotecas. Ideias Emergentes em Biblioteconomia, São Paulo, p. 69-77, 2016.

MANOVICH, Lev. The language of new media. Cambridge, MA: MIT Press, 2001. 400p.

NASSI-CALÒ, L. A revisão por pares como objeto de estudo. SciELO em Perspectiva, São Paulo, 2015. Disponível em: https://blog.scielo.org/blog/2015/04/24/a-revisao-por-parescomo-objeto-de-estudo/. Acesso em: 08 dez. 2020. 
OLIVEIRA, L. A. R. Bibliotecas: uma breve revisão histórica. 52 p. Monografia (Graduação em Biblioteconomia) - Universidade Federal do Rio Grande do Norte, Natal, 2019.

PRETTO, N. Redes colaborativas, ética hacker e educação. Educação em Revista, Belo Horizonte, v. 26, n. 3, p. 305-316, 2010.

PINTO, S. L. U. et al. O movimento maker: enfoque nos fablabs brasileiros. Revista Livre de Sustentabilidade e Empreendedorismo, Paraná, v. 3, n. 1, p. 38 - 56, 2018.

RAMOS, A.; FARIA, P. M.; FARIA, A. Revisão sistemática de literatura: contributo para a inovação na investigação em Ciências da Educação. Revista Diálogo Educacional, Curitiba, v. 14, n. 41, p. 17-36, 2014.

SANTOS, R. G.; CÂNDIDO, A. C. Bibliotecas como makerspace: oportunidades de implementação a partir de um caso prático. Ciência da Informação em Revista, Maceió, v. 6, n. 1, p. 114-125, maio 2019.

SILVA, A. P. O embate entre a pedagogia tradicional e a educação nova: políticas e práticas educacionais na escola primária catarinense (1911-1945). In: SEMINÁRIO DE PESQUISA EM EDUCAÇÃO DA REGIÃO SUL, 9., 2012, Santa Catarina. Apresentações. Caxias do Sul: Universidade de Caxias do Sul, 2012. Disponível em: http://www.ucs.br/etc/conferencias/index.php/anpedsul/9anpedsul/paper/viewFile/1259/13. Acesso em: 2 dez. 2021.

SILVEIRA, S. A. Diversidade digital e cultura. 19 jun. 2007. Disponível em: https://diversidadedigital.blogspot.com/2007/06/effective-opensource.html. Acesso em: 2 dez. 2021.

VIEIRA, D. V. Inovação em bibliotecas: considerações sobre a disponibilização de serviço de impressão 3D. Revista Brasileira de Biblioteconomia e Documentação, São Paulo, v. 13, p. 1106-1120, 2017.

ZANINELLI, T. B.; SANTOS NETO, J. A. Biblioteca escolar com makerspace: um estudo de caso na Biblioteca Abraham Lincoln. Revista Brasileira de Biblioteconomia e Documentação, São Paulo, v. 13, p. 2633-2655, 2017. 